\title{
A New Regimen in the Treatment of Psoriasis Using Oral Methotrexate
}

\author{
Khalifa E. Sharquie ${ }^{1,2^{*}}$, Adil A. Noaimi ${ }^{1,2}$, Mays H. Alobaidi ${ }^{2}$ \\ ${ }^{1}$ Department of Dermatology, College of Medicine, University of Baghdad, Baghdad, Iraqi \\ ${ }^{2}$ Center of Dermatology and Venereology, Medical City, Baghdad, Iraq \\ Email: ^ksharquie@ymail.com, adilnoaimi@yahoo.com, muhakobaidy@gmail.com
}

How to cite this paper: Sharquie, K.E., Noaimi, A.A. and Alobaidi, M.H. (2019) A New Regimen in the Treatment of Psoriasis Using Oral Methotrexate. Journal of Cosmetics, Dermatological Sciences and Applications, 9, 165-176.

https://doi.org/10.4236/jcdsa.2019.92014

Received: April 18, 2019

Accepted: June 2, 2019

Published: June 5, 2019

Copyright (c) 2019 by author(s) and Scientific Research Publishing Inc. This work is licensed under the Creative Commons Attribution International License (CC BY 4.0).

http://creativecommons.org/licenses/by/4.0/

\begin{abstract}
Background: Methotrexate is a well-known standard therapy for psoriasis. The standard regimen is using six $(2.5 \mathrm{mg})$ tablets/week that might be with many side effects. Objective: Finding a new regimen for oral methotrexate aiming to decrease side effects and increase its effectiveness. Patients and Methods: This therapeutic, comparative study done at the Center of Dermatology, Medical city, from October 2017 to October 2018. Fifty-three patients with moderate to severe psoriasis completed the study. They were divided into: Group (A) (27) patients were treated with the new oral regimen and Group (B) (26) patients were treated with the six tablets/week. Investigations including CBC, LFT and RFT were done. PASI score, BSA and side effects especially gastrointestinal ones were recorded. Results: They were 29 males and 24 females. Age ranged from 18 - 67 years. Disease duration ranged from 1 - 30 years. BSA involved ranged from $20 \%-79 \%$. The PASI score ranged from 10.2 - 45.7. After 8 weeks of treatment, there was statistically significant difference ( $p$-value $>0.001)$ regarding PASI score and gastrointestinal side effects being less in Group (A). Group A patients were more satisfied. Conclusion: The new regimen used in the present study has lower gastrointestinal side effects and more efficacy.
\end{abstract}

\section{Keywords}

Psoriasis, Methotrexate, New Regimen

\section{Introduction}

Psoriasis is a common skin problem for which there are many different topical and systemic therapies. It is heterogeneous in its morphology, affected sites, natural history, and age at onset, duration and precipitating factors [1]. It is 
universal in occurrence; its prevalence in different populations varies from $0.1 \%$ to $11.8 \%$, according to published reports [2]. Both genetic and environmental factors have a critical role in the etiology and pathogenesis of psoriasis [1]. Plaque psoriasis is the most common type of psoriasis, accounting for about $80 \%$ $90 \%$ of all cases [3]. Treatment depends upon many variables including age, gender, occupation, personality, general health, intelligence and resources, as well as the type, extent, site, duration and natural history of the disease [1].

Methotrexate has been since long time used for treatment of psoriasis as an effective therapy. It is a potent competitive antagonist of the enzyme dihydrofolate reductase; this leads to inhibition of DNA synthesis at the S phase. It was approved by the FDA for the treatment of psoriasis since 1971. Jeffes and colleagues [4] demonstrated in an in vitro experiment that the effect of MTX on the proliferation of lymphoid cells is 1000 times greater than its effect on human keratinocytes. Thus, at concentrations reached in vivo, it is most likely that MTX acts via an immunosuppressive mechanism, rather than as antiproliferative agent directed against the keratinocyte. Sigmundsdottir and colleagues [5] have demonstrated depression of cutaneous lymphocyte-associated antigen-positive $\mathrm{T}$ cells and endothelial E-selectin in MTX-treated psoriatic patients. Methotrexate can be administered orally, IV, IM and SC, with the oral route providing the most reliable blood level [6].

Methotrexate once weekly by Weinstein regimen [7] (triple 12 hourly doses) is still used as the standard regimen in the treatment of psoriasis.

Objective of the present work is to find another regimen to minimize side effects and enhance the efficacy.

\section{Patients and Methods}

This therapeutic, comparative, study was carried out at the Centre of Dermatology and Venereology, Medical City, from October 2017 to October 2018. Informed consent was taken from each patient before starting the therapy, after full explanation about the nature of the disease, course, the regimen of treatment, possible side effects and timing of follow up visits. In addition, the scientific committee of the Scientific Council of Dermatology and Venereology-Arab Board for Health Specializations gave the ethical approval.

Inclusion criteria: those patients with moderate to severe plaque psoriasis with PASI score equal or more than 10 and BSA affected by psoriasis of $20 \%$ or more.

Exclusion criteria: pregnancy, lactation, liver disease, unreliable patient - including excessive alcohol intake (>100 g/week), decreased renal function, uncontrolled diabetes mellitus, morbid obesity and severe hematologic abnormalities. Also man or woman contemplating conceptions, active infectious disease or history of potentially serious infection that could reactivate (such as TB), immunodeficiency syndrome: hereditary or acquired, active peptic ulcer and those patients taking any topical or systemic psoriasis treatment for the last 2 months. 
The diagnosis was made on clinical basis. History was taken regarding name of patient, gender, age, duration of disease, previous treatments used including topical and systemic therapies and response to them, the presence of associated illnesses and their treatments. In addition, if there is any plan to conceive and methods used for contraception, history or recent alcohol consumption. Physical examination of the patients was done to assess the site, surface area and severity of psoriasis using PASI score and photographs was taken using Samsung Galaxy Grand 2 (SM-G7102) camera of 8 megapixels with same illumination and distance. PASI score was calculated as the following:

1) Severity of psoriatic lesions: The body was divided into four regions including the head, upper extremities, trunk, and lower extremities. The psoriatic plaques were graded according to the following three criteria: Redness, thickness, and scaling each was assigned as a number starting from 0 to 4 with 4 being the worst. Then the three index scores were added up for each of the four body regions to give subtotals A1, A2, A3, and A4. Each subtotal is then multiplied by the body surface area represented by that region.

- $\mathrm{A} 1$ (head) $\times 0.1=\mathrm{B} 1$

- $\mathrm{A} 2$ (upper limbs) $\times 0.2=\mathrm{B} 2$

- $\mathrm{A} 3$ (trunk) $\times 0.3=\mathrm{B} 3$

- A4 (lower limbs) $\times 0.4=\mathrm{B} 4$

2) Area of psoriatic involvement: In each of these areas, the fraction of total surface area affected is graded on a 0 - 6 scale (zero for no involvement; up to 6 for greater than $90 \%$ involvement). And then each of the body area scores was multiplied by the area affected.

- $\mathrm{B} 1 \times(0$ to 6$)=\mathrm{C} 1$

- $\mathrm{B} 2 \times(0$ to 6$)=\mathrm{C} 2$

- $\mathrm{B} 3 \times(0$ to 6$)=\mathrm{C} 3$

- $\mathrm{B} 4 \times(0$ to 6$)=\mathrm{C} 4$

3) The PASI score is the summation of $\mathrm{C} 1+\mathrm{C} 2+\mathrm{C} 3+\mathrm{C} 4$.

The highest potential PASI score is 72; the lowest is 0 [8].

A total of 60 patients with moderate to severe plaque-type psoriasis were enrolled but only 53 patients completed the study for both the treatment and follow up period. While 7 patients were considered to be defaulted for several reasons including difficulty in transport. All patients underwent the following laboratory tests at baseline: a complete blood count, serum creatinine, blood urea nitrogen, aspartate aminotransferase, alanine aminotransferase, alkaline phosphatase, and bilirubin.

Patients were divided randomly into two groups according to their treatment regimen:

Group A: twenty-seven patients received the tested new regimen in which the patient was instructed to take three methotrexate $(2.5 \mathrm{mg})$ tablets, one tablet every 8 hours and every 3 days.

Group B: twenty-six patients received the known Weinstein regimen [7] in 
which the patient was instructed to take six methotrexate $(2.5 \mathrm{mg})$ tablets, 2 tablets every 12 hours and once weekly.

Methotrexate $(2.5 \mathrm{mg})$ tablets were provided to the patients by the pharmacy of Baghdad center of dermatology. Patients were assessed at five visits during their treatment period: At week zero, week 2, week 4, week 6 and week 8. In addition, each patient had additional follow up period ranging from 8 to 16 weeks during which MTX was tapered to be stopped. Patients were asked at each visit if they had any problems with taking MTX without direct questioning except for symptoms referable to the gastrointestinal tract for which direct questions were asked regarding a list of specific gastrointestinal symptoms (mouth ulcers, nausea, vomiting, abdominal pain, diarrhea and gastrointestinal hemorrhage) and the replies recorded. The following points were clarified in those patients experiencing gastrointestinal symptoms: onset of symptoms in relation to MTX ingestion, duration and severity of symptoms, MTX dose eliciting symptoms, and action taken to avoid symptoms. In addition, at each visit CBC and LFT was done and values were recorded. Also PASI score was recorded at each visit. After completing 8 weeks of treatment, patients' satisfaction regarding response to treatment and side effects were recoded. Patients who came back with relapse after stopping the treatment were also recorded after a follow up period ranging from 4 to 6 months.

\section{Statistical Analysis}

The data analyzed using Statistical Package for Social Sciences (SPSS) version 25. The data was presented as mean, standard deviation and ranges. Two-sample $\mathrm{t}$-test was used for comparison between variables. $\mathrm{P}$ value of less than 0.05 was considered significant.

\section{Results}

A total of 53 patients with moderate to severe plaque-type psoriasis who completed the study were assessed during the two months treatment period. They were $29(54.71 \%)$ males and $24(45.28 \%)$ females (Table 1$)$. Their ages ranged from 18 - 67 years with a mean \pm SD of $35.55 \pm 12.98$ years. Their disease duration ranged from $1-30$ years with a mean \pm SD of $9.39 \pm 7.14$ years. Their BSA involved with psoriasis ranged from $20 \%-79 \%$ with a mean \pm SD of $44.28 \% \pm$ $16.78 \%$. Their PASI score ranged from $10.2-45.7$ with a mean \pm SD of $25.08 \pm$ 9.67. There was no statistically significant difference between the patients in the two groups regarding the age, disease duration, BSA of psoriasis, and the baseline PASI score (Table 2).

Group A: In this group, there were 15 (55.6\%) males and 12 (44.4\%) females. Their age ranged from $18-63$ years with mean \pm SD of $34.14 \pm 12.29$ years and the duration of their disease ranged from $1-20$ years with mean \pm SD of $7.98 \pm$ 5.26 years. The BSA involved with psoriasis in the patients of this group ranged from $20 \%-75 \%$ with mean \pm SD of $43.07 \% \pm 18.06 \%$. Their PASI score ranged 
from $10.2-45.7$ with a mean \pm SD of $23.42 \pm 9.90$.

Group B: In this group, there were 14 (53.8\%) males and 12 (46.2\%) females. Their age ranged from $18-67$ years with mean \pm SD of $36.96 \pm 13.67$ years and the duration of their disease ranged from $1-30$ years with mean \pm SD of $10.89 \pm$ 9.02 years. The BSA involved with psoriasis ranged from $25 \%-79 \%$ with mean \pm SD of $45.50 \% \pm 15.51 \%$. Their PASI score ranged from $12.5-45.3$ with mean \pm SD of $26.75 \pm 9.44$.

\section{Reported gastrointestinal side effects (Table 3 )}

After 8 weeks of treatment with methotrexate in these two groups, the reported gastrointestinal side effects were as follow:

Group A: Nausea was reported by $4(14.8 \%)$ patients, vomiting was reported by $2(7.41 \%)$ patients, abdominal pain was reported by $1(3.7 \%)$ patient and diarrhea was reported by $2(7.41 \%)$ patients. Any patient in this group reported neither oral ulcerations nor melena.

Group B: Nausea was reported by 15 (57.7\%) patients, vomiting was reported by $7(26.9 \%)$ patients, abdominal pain was reported by $6(23.1 \%)$ patients, diarrhea was reported by $3(11.5 \%)$ patients and oral ulceration was reported by 1 (3.85\%) patient. No patient in this group reported melena.

\section{Reduction in the hematological indices (Table 4):}

Group A: At the end of the 8 weeks treatment, the mean \pm SD of the reduction in the $\mathrm{Hb}$ was $0.18 \pm 0.89 \mathrm{~g} / \mathrm{dL}$, while that of the $\mathrm{WBC}$ was $2.10 \pm 2.1410^{3} / \mathrm{uL}$, and of the Platelets count was $18 \pm 27.0110^{3} / \mathrm{uL}$.

Group B: At the end of the 8 weeks treatment the mean $\pm \mathrm{SD}$ in the $\mathrm{Hb}$ was $1.42 \pm 1.31 \mathrm{~g} / \mathrm{dL}$, while that of the WBC was $1.96 \pm 2.2610^{3} / \mathrm{uL}$, and of the Platelets count was $22.93 \pm 36.9810^{3} / \mathrm{uL}$.

There was no statistically significant difference $(\mathrm{P}-\mathrm{Value}>0.05)$ in the reductions of the three hematological indices ( $\mathrm{Hb}, \mathrm{WBC}$, Platelets) between the two groups.

\section{Elevation in liver enzymes (ALT, AST) (Table 5):}

Group A: at the end of the 8 weeks of treatment the mean \pm SD of the elevation in the AST was $10.07 \pm 12.14 \mathrm{U} / \mathrm{L}$ and that of the ALT was $34.69 \pm 42.18$ U/L.

Group B: at the end of the 8 weeks of treatment the mean \pm SD of the elevation in the AST was $12 \pm 16.88 \mathrm{U} / \mathrm{L}$ and that of the ALT was $20.18 \pm 21.86 \mathrm{U} / \mathrm{L}$.

There was no statistically significant difference $(\mathrm{P}-\mathrm{Value}>0.05)$ in the elevations of the AST and ALT between the two groups.

PASI Score at each visit in the two groups (Table 6, Figure 1, and Figure 2):

Group A: at baseline visit mean \pm SD of PASI score was $23.42 \pm 9.90$, at the 2 weeks visit it was $18.55 \pm 9.37$, at the 4 weeks visit was $13.45 \pm 6.92$, at the 6 weeks visit was $8.47 \pm 4.97$, and at the 8 weeks it was $4.06 \pm 3.85$.

Group B: at baseline visit mean \pm SD of PASI score was $26.75 \pm 9.44$, at the 2 weeks visit it was $23.12 \pm 9.85$, at the 4 weeks visit was $19.45 \pm 8.82$, at the 6 weeks visit was $15.23 \pm 7.36$, and at the 8 weeks it was $9.13 \pm 6.15$. 

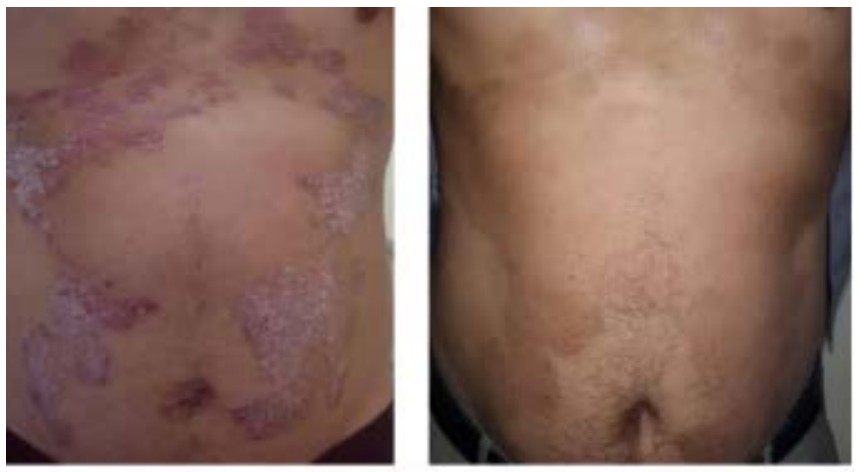

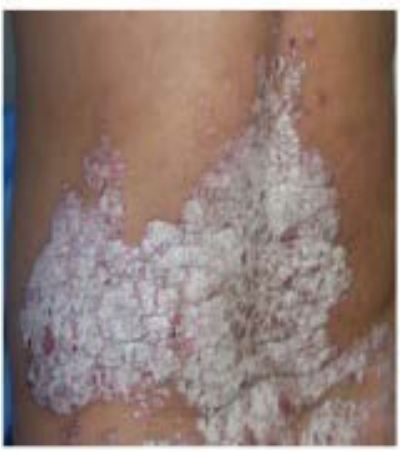

(a)

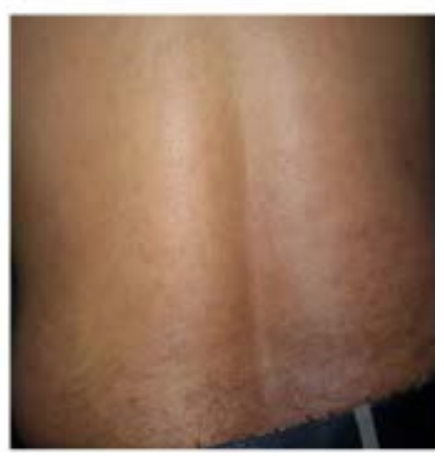

(b)

Figure 1. Sixty-two years old patient on the new oral regimen (a) before and (b) after eight weeks of treatment.
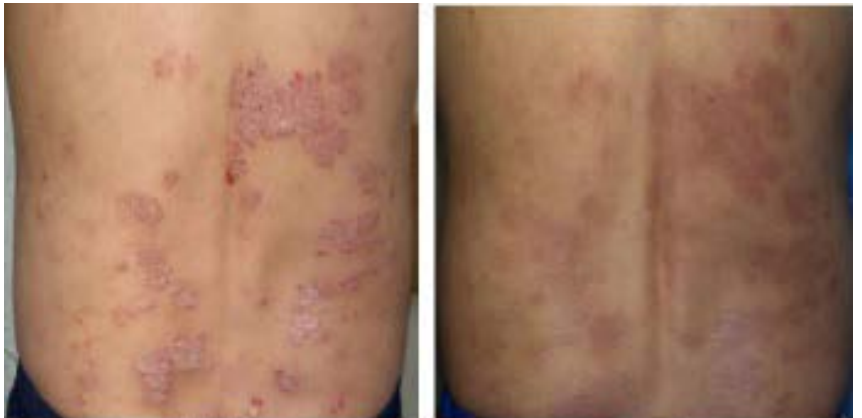

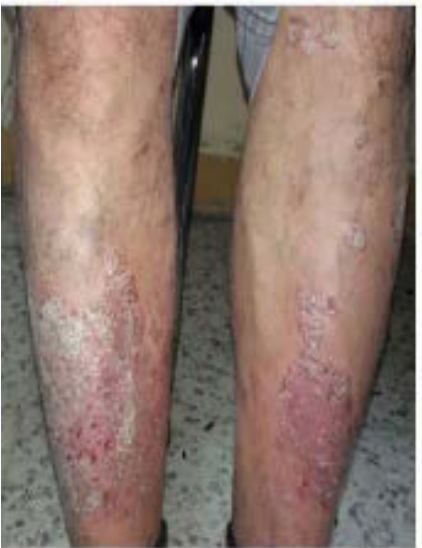

(a)

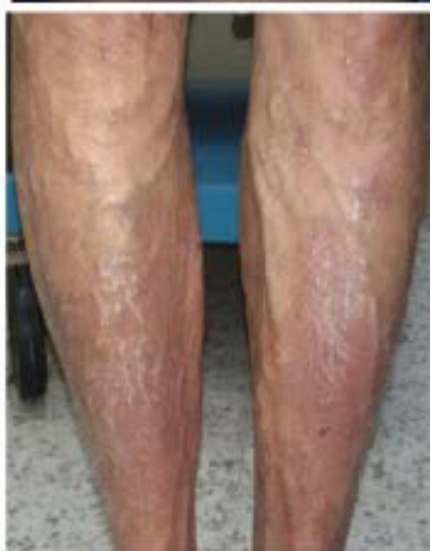

(b)

Figure 2. Fifty-three years old patient on the once weekly regimen (a) before and (b) after eight weeks of treatment. 
Table 1. Gender distribution in the two study groups.

\begin{tabular}{cccccc}
\hline Gender & \multicolumn{2}{c}{ Group A } & \multicolumn{2}{c}{ Group B } & P value \\
\hline & No. & Percent & No. & Percent & \\
Male & 15 & 55.6 & 14 & 53.8 & $>0.05$ \\
Female & 12 & 44.4 & 12 & 46.2 & NS \\
Total & 27 & 100.0 & 26 & 100.0 & \\
\hline
\end{tabular}

Table 2. Demographic criteria of the patients in the two study groups.

\begin{tabular}{ccccccccc}
\hline $\begin{array}{c}\text { Patient } \\
\text { characteristics }\end{array}$ & Groups & No. & Min. & Max. & Mean & SD & P-value & Sig \\
\hline \multirow{2}{*}{ Age } & Group A & 27 & 18.00 & 63.00 & 34.148 & 12.296 & & \\
& Group B & 26 & 18.00 & 67.00 & 36.960 & 13.677 & & NS \\
$\begin{array}{c}\text { Duration } \\
\text { (Years) }\end{array}$ & Group A & 27 & 1.00 & 20.00 & 7.981 & 5.263 & & \\
& Group B & 26 & 1.00 & 30.00 & 10.892 & 9.026 & & NS \\
BSA (\%) & Group A & 27 & 20.00 & 75.00 & 43.074 & 18.06383 & & \\
& Group B & 26 & 25.00 & 79.00 & 45.500 & 15.51322 & & \\
& Group A & 27 & 10.2 & 45.7 & 23.422 & 9.909 & & \\
Baseline PASI & Group B & 26 & 12.5 & 45.3 & 26.750 & 9.446 & & \\
& & & & & & & & NS \\
\hline
\end{tabular}

Table 3. Comparison of the gastrointestinal side effects between the study groups with $\mathrm{P}$-value.

\begin{tabular}{cccccc}
\hline & \multicolumn{2}{c}{ Group A } & \multicolumn{2}{c}{ Group B } & P-value \\
Side effect & No. & $\%$ & No. & $\%$ & \\
\hline Nausea & 4 & 14.8 & 15 & 57.7 & $\mathrm{P}<0.001$ \\
Vomiting & 2 & 7.41 & 7 & 26.9 & $\mathrm{P}<0.001$ \\
Abdominal pain & 1 & 3.7 & 6 & 23.1 & $\mathrm{P}<0.001$ \\
Oral ulceration & 0 & 0 & 1 & 3.85 & $\mathrm{P}>0.05$ \\
Diarrhea & 2 & 7.41 & 3 & 11.5 & 0.879 \\
Melena & 0 & 0 & 0 & 0 & - \\
\hline
\end{tabular}

Table 4. Comparisons between reductions in the hematological indices ( $\mathrm{Hb}, \mathrm{WBC}$, Platelets) of the two groups after 8 weeks of treatment.

\begin{tabular}{cccc}
\hline $\begin{array}{c}\text { Groups } \\
\text { Hematological } \\
\text { Indices }\end{array}$ & $\begin{array}{c}\text { Group A } \\
\text { Mean } \pm \text { SD }\end{array}$ & $\begin{array}{c}\text { Group B } \\
\text { Mean } \pm \text { SD }\end{array}$ & P value \\
\hline $\mathrm{Hb}(\mathrm{g} / \mathrm{dL})$ & $0.18 \pm 0.89$ & $1.42 \pm 1.31$ & 0.208 \\
$\mathrm{WBC}\left(10^{3} / \mathrm{uL}\right)$ & $2.10 \pm 2.14$ & $1.96 \pm 2.26$ & 0.887 \\
Platelets $\left(10^{3} / \mathrm{uL}\right)$ & $18.00 \pm 27.01$ & $22.93 \pm 36.98$ & 0.715 \\
\hline
\end{tabular}


Table 5. Comparisons between increments in the liver enzymes (AST, ALT) of the two groups after 8 weeks of treatments.

\begin{tabular}{cccc}
\hline $\begin{array}{c}\text { Groups } \\
\text { Liver } \\
\text { Enzymes }\end{array}$ & $\begin{array}{c}\text { Group A } \\
\text { Mean } \pm \text { SD }\end{array}$ & $\begin{array}{c}\text { Group B } \\
\text { Mean } \pm \text { SD }\end{array}$ & P value \\
\hline AST (U/L) & $10.07 \pm 12.14$ & $12.00 \pm 16.88$ & 0.710 \\
ALT (U/L) & $34.69 \pm 42.18$ & $20.18 \pm 21.86$ & 0.338 \\
\hline
\end{tabular}

Table 6. Comparison of PASI score between the two groups at each visit.

\begin{tabular}{ccccccc}
\hline & \multicolumn{2}{c}{ Group A } & \multicolumn{2}{c}{ Group B } & \multirow{2}{*}{ P-value } & Sig \\
\cline { 2 - 5 } & Mean & SD & Mean & SD & & \\
\hline Baseline & 23.422 & 9.909 & 26.750 & 9.446 & 0.103 & NS \\
Second week & 18.559 & 9.373 & 23.126 & 9.855 & 0.025 & S \\
Four week & 13.459 & 6.927 & 19.457 & 8.825 & 0.002 & S \\
Six week & 8.470 & 4.979 & 15.234 & 7.360 & 0.000 & HS \\
Eight week & 4.066 & 3.851 & 9.134 & 6.159 & 0.000 & HS \\
\hline
\end{tabular}

There was statistically significant difference $(\mathrm{P}-\mathrm{Value}<0.05)$ between the PASI score of the two groups at the 2 weeks and 4 weeks visit and there was highly significant difference $(\mathrm{P}-\mathrm{Value}<0.0001)$ between the PASI score of the two groups at the 6 and 8 weeks visits being more decreased in group A.

Patients' satisfaction regarding response to treatment and side effects (Table 7):

Group A: regarding response to treatment and side effects 17 (62.96\%) patients were very satisfied, $8(29.62 \%)$ were satisfied and only $2(7.40 \%)$ were not satisfied.

Group B: regarding response to treatment and side effects 9 (34.61\%) patients were very satisfied, 10 (38.46\%) were satisfied and 7 (26.92\%) were not satisfied.

There was statistically significant difference $(\mathrm{P}$ value $<0.05)$ between the two groups with those in group A being more satisfied regarding the response to treatment and side effects.

Relapse after a follow up period ranging from four to six months (Table 8):

Group A: after stopping the treatment, only $2(7.40 \%)$ patients reported relapse.

Group B: after stopping the treatment, 7 (26.92\%) patients reported relapse.

There was statistically significant difference $(P$ value $<0.05)$ regarding the relapse being less in group A.

\section{Discussion}

Psoriasis is a known common, chronic, inflammatory and proliferative condition of the skin. In some longitudinal studies that have been done, spontaneous remission occurs in between a third and a half of patients, and has been reported 
Table 7. Patients' satisfaction regarding response to treatment and side effects in the two groups.

\begin{tabular}{ccccccccc}
\hline \multicolumn{3}{c}{ Very satisfied } & \multicolumn{3}{c}{ Satisfied } & \multicolumn{3}{c}{ Not satisfied } \\
\hline Group A & Group B & P value & Group A & Group B & P value & Group A & Group B & P value \\
N (\%) & $\mathrm{N}(\%)$ & & $\mathrm{N}(\%)$ & $\mathrm{N}(\%)$ & & $\mathrm{N}(\%)$ & $\mathrm{N})$ & \\
$17(62.96)$ & $9(34.61)$ & 0.008 & $8(29.62)$ & $10(38.46)$ & 0.053 & $2(7.40)$ & $7(26.92)$ & 0.048 \\
\hline
\end{tabular}

Table 8. Relapse of the psoriasis in the two study groups.

\begin{tabular}{ccc}
\hline $\begin{array}{c}\text { Patient relapsed } \\
\text { in group A N (\%) }\end{array}$ & $\begin{array}{c}\text { Patients relapsed } \\
\text { in group B N (\%) }\end{array}$ & P value \\
\hline $2(7.40)$ & $7(26.92)$ & 0.048 \\
\hline
\end{tabular}

for as long as 54 years. The cause of these spontaneous remissions is not well recognized. There is little doubt that even severe cases can be maintained in prolonged remission by the use of different systemic therapies [9]. Untreated, relapse is the rule, however completely the lesions have been treated and by whatever method. The time to relapse might vary greatly between patients and among different therapeutic modalities [1].

From the above-mentioned prognosis of psoriasis, it is obvious that the need to use systemic treatment in psoriasis will be forced sooner or later and that the course of this treatment will usually be either prolonged or repetitive. In addition, the association of psoriasis with other systemic manifestations such as psoriatic arthritis will necessitate the need for systemic treatment.

As methotrexate is well known for its prolonged history of effectiveness in the treatment of different varieties of psoriasis as well as its relatively low cost, it is the first systemic therapy to be considered.

Methotrexate (4-amino-N methyl pteroylglutamic acid) is a well-known potent competitive antagonist (inhibitor) of the enzyme dihydrofolate reductase. It has many similarities to the structure of folic acid, the natural substrate for this enzyme, differing from folic acid in only two molecular sites [4].

Although methotrexate is thought to inhibit keratinocyte hyperproliferation but it appears in addition to inhibit lymphocyte proliferation more profoundly and probably acts through this mechanism in psoriasis and psoriatic arthritis [6].

The ordinary dose of oral methotrexate is different but might reach to a maximum of $30 \mathrm{mg}$ weekly; in addition, it can be given by intramuscular or subcutaneous injection [10].

Guidelines regarding the dosing regimen for MTX are partially based on expert opinions that vary in their recommendations. In daily clinical practice, there is a wide variety of dosing regimens and patients with psoriasis are often undertreated [11]. Barker et al. have identified a number of key questions about MTX therapy for psoriasis and have emphasized the need for appropriate studies to determine optimal dosing with regard to efficacy and safety [12]. 
A survey of dermatologists worldwide identified that the clinical use of MTX in psoriasis is not uniform and is not in full agreement with clinical guidelines [13]. From the above we would conclude that an oral methotrexate regimen is not well established.

The most popular regimen for methotrexate in psoriasis is Weinstein regimen (weekly 12 hours interval triple dose) [7]. The aim of his regimen was to decrease the side effects of methotrexate and increase its efficacy. In his study 26 patients were concluded and from them 15 (57.69\%) patients complain from nausea while abdominal pain, diarrhea and melena were not recorded. Also this regimen was thought to synergize with the cell cycle kinetics when psoriasis was thought previously to be a disease of keratinocytes hyperproliferation and as this concept was proven to wrong the remaining only indication to it is use was to decrease the gastrointestinal side effects of oral methotrexate.

Nevertheless this regimen could not be tolerated by every patient; accordingly, the present work was arranged aiming to find new oral regimen of methotrexate ( 3 tablets every 3 days) in order to minimize or prevent the side effects especially the gastrointestinal side effects that might oblige the patient to stop treatment, in addition trying to increase its efficacy.

In the present study after 8 weeks of treatment with methotrexate in the two groups comparison between the reported side effects showed that there was statistically high significant difference ( $\mathrm{p}$-value $>0.001)$ regarding the nausea, vomiting and abdominal pain being less in group A taking the new oral regimen. While difference in the reductions in hematological indices (CBC, WBC, Platelets) between the two groups was not statistically significant (P-Value $>0.05$ ). Also difference in the elevations in the liver enzymes (AST, ALT) was not significant $(\mathrm{P}-$ Value $>0.05)$. Regarding PASI score, there was statistically significant difference $(\mathrm{P}-\mathrm{Value}<0.0001)$ in between the two groups at all follow up visits being less in value in group $A$.

In addition, there was statistically significant difference $(\mathrm{P}$ value $<0.05)$ regarding relapse rate being less with the new oral regimen. Also there was statistically significant difference $(P$ value $<0.05$ ) when comparing patients satisfaction regarding response and side effects with patients taking the new oral regimen being more satisfied.

So according to these results, it appeared that this new regimen had lower gastrointestinal side effects, more efficacy and lesser relapse rate and patients taking this regimen were more satisfied and thus we recommend this new regimen of treatment of chronic plaque psoriasis. Still further studies might be needed to be carried out at different centers to re-evaluate this new method of oral methotrexate treatment of psoriasis.

\section{Conclusions}

Reviewing the results of the present study, we can conclude the followings:

1) Gastrointestinal side effects significantly decreased. 
2) Efficacy of methotrexate was significantly increased.

3) Patients were more satisfied regarding response to treatment and side effect.

4) Relapse rates after stopping treatment were significantly less in this new regimen.

Hence, we can conclude that twice a week dose is highly recommended than once a week dose.

\section{Disclosure}

This study was independent and not funded by any drug company or organization.

\section{Conflicts of Interest}

The authors declare no conflicts of interest regarding the publication of this paper.

\section{References}

[1] Burden, A.D. and Kirby, B. (2016) Psoriasis and Related Disorders. In: Griffiths, C., Barker, J., Bleiker, T., Chalmers, R. and Creamer, D., Eds., Rook's Textbook of Dermatology, 9th Edition, John Wiley \& Sons, New Delhi, 1-48. https://doi.org/10.1002/9781118441213

[2] Gudjonsson, J.E. and Elder, J.T. (2012) Psoriasis. In: Wolff, K., Goldsmith, L.A., Katz, S.I., Gilchrest, B.A., Paller, A.S. and Leffell, D.J., Eds., Fitzpatrick's Dermatology in General Medicine, 8th Edition, The McGraw-Hill Companies, Singapore, 197-231. https://doi.org/10.1111/j.1524-4725.2008.34211.x

[3] Bowcock, A.M. and Krueger, J.G. (2005) Getting under the Skin: The Immunogenetics of Psoriasis. Nature Reviews Immunology, 5, 699-711.

[4] Jeffes III, E.W.B., McCullough, J.L. and Pittelkow, M.R. (1995) Methotrexate Therapy of Psoriasis. Differential Sensitivity of Proliferating Lymphoid and Epithelial Cells to the Cytotoxic and Growth-Inhibitory Effects of Methotrexate. Journal of Investigative Dermatology, 104, 183-188. https://doi.org/10.1111/1523-1747.ep12612745

[5] Sigmundsdottir, H., Johnston, A. and Gudjonsson, J.E. (2004) Methotrexate Markedly Reduces the Expression of Vascular E-Selectin, Cutaneous Lymphocyte-Associated Antigen and the Numbers of Mononuclear Leucocytes in Psoriatic Skin. Experimental Dermatology, 13, 426-434. https://doi.org/10.1111/j.0906-6705.2004.00177.x

[6] Callen, J.P. and Kulp-Shorten, C.L. (2012) Methotrexate. In: Wolverton, S.E., Ed., Comprehensive Dermatologic Drug Therapy, 3rd Edition, Elsevier Inc., London, 169-181.

[7] Weinstein, G.D. and Frost, P. (1971) Methotrexate for Psoriasis: A New Therapeutic Schedule. Archives of Dermatology, 103, 33-38.

https://doi.org/10.1001/archderm.103.1.33

[8] https://www.dermnetnz.org/topics/pasi-score/

[9] Lomholt, G. (1963) Psoriasis: Prevalence, Spontaneous Course and Genetics. GEC Gad, Copenhagen, 78-189. 
[10] Warren, R.B., Chalmers, R.J.G., Griffiths, C.E.M. and Menter, A. (2008) Methotrexate for Psoriasis in the Era of Biological Therapy. Clinical and Experimental Dermatology, 33, 551-554. https://doi.org/10.1111/j.1365-2230.2008.02976.x

[11] Menting, S.P., Dekker, P.M., Limpens, J., Hooft, L. and Spuls, P.I. (2016) Methotrexate Dosing Regimen for Plaque-Type Psoriasis: A Systematic Review of the Use of Test-Dose, Start-Dose, Dosing Scheme, Dose Adjustments, Maximum Dose and Folic Acid Supplementation. Acta Dermato-Venereologica, 96, 23-29. https://doi.org/10.2340/00015555-2081

[12] Barker, J., Horn, E.J., Lebwohl, M., Warren, R.B., Nast, A. and Rosenberg, W. (2011) Assessment and Management of Methotrexate Hepatotoxicity in Psoriasis Patients: Report from a Consensus Conference to Evaluate Current Practice and Identify Key Questions toward Optimizing Methotrexate Use in the Clinic. Journal of the European Academy of Dermatology and Venereology, 25, 758-764. https://doi.org/10.1111/j.1468-3083.2010.03932.x

[13] Gyulai, R., Bagot, M., Griffiths, C.E., Luger, T., Naldi, L. and Paul, C. (2015) Current Practice of Methotrexate Use for Psoriasis: Results of a Worldwide Survey among Dermatologists. Journal of the European Academy of Dermatology and Venereology, 29, 224-231. https://doi.org/10.1111/jdv.12495 